\title{
e-Interview
}

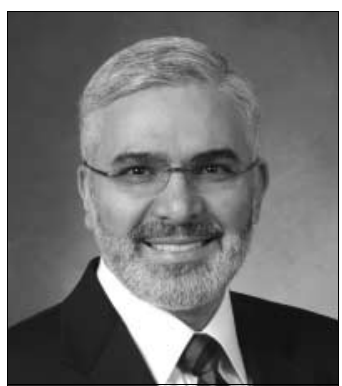

\section{Henry A. Nasrallah, MD}

Henry A. Nasrallah is Professor of Psychiatry and Neuroscience at the University of Cincinnati College of Medicine. He trained in psychiatry at the University of Rochester and received his neuroscience research fellowship at the National Institute of Mental Health (NIMH). His special interests include the neurobiology and psychopharmacology of schizophrenia and the related disorders.

If you were not a psychiatrist, what would you do?

Ophthalmology. I really enjoyed that experience. However, it was still a distant second to psychiatry. Many years after I became a psychiatrist, it dawned on me that I chose insight over sight.

What has been the greatest impact of your profession on you personally?

Psychiatry not only honed my empathy, enabled me to tolerate ambiguity and enhanced my creativity, but I believe it made me wiser than I would have been had I chosen a manual-skill medical specialty like surgery or a visual-skill specialty like radiology. I attribute that to the pre-frontal neuroplasticity that psychotherapy stimulates by nature of concept formation, nuanced thinking, cognitive problemsolving and pro-social stance inherent in psychiatric practice. Had I become a surgeon, my fingers' motor area would have hypertrophied instead and had I become a radiologist, my visual cortical connections would have expanded. I am glad I had prefrontal lobe neuroplasticity instead.

\section{Do you feel stigmatised by your} profession?

On the contrary, I feel fortunate to be a psychiatrist and to help diffuse the stigma of mental illness through intensive public education, teaching and training future physicians, conducting research and discovering the biological roots of psychiatric disorders, and providing evidence-based and compassionate clinical care that improves lives, one patient at a time.
What are your interests outside of work?

Outside spending time with my family (especially my five little grandchildren), I enjoy editing my two journals (Schizophrenia Research and Current Psychiatry), exercising (walking, tennis and swimming),

volunteering, and reading about culture and philosophy. I do love playing chess and word games like scrabble on my iPad!

If I knew in college what I know now, would I have still chosen academic psychiatry as a career?

Beyond a shadow of a doubt! I am still as eager to go to work every morning now as I was 30 years ago. Doing research, teaching, mentoring and treating the most complicated psychiatric patients is a most wonderful life!

\section{Which publication has influenced you} most?

The British Journal of Psychiatry (BJP), which I read avidly during medical school and which instigated me to become a researcher. Interestingly, George Winokur, whose work I used to read in the BJP, recruited me to his department 4 years after completing my training even though I had never met him in person. I loved working with him for 6 years before I became a chairman myself.

How has the political environment influenced your work?

I just wish there was less intrusion from the legal system into psychiatry because it has led to wholesale criminalisation and imprisonment of patients with serious mental illness. Our patients have been transformed to felons, and politicians are far more willing to build prisons than long-term psychiatric hospitals. Psychiatrists and families must wake up and fight this ominous trend that punishes people with brain disorders.

\section{What part of your work gives you the} most satisfaction?

Research and discovering causes and new treatments of psychotic disorders is the spice of my life, but I get a big buzz from teaching and mentoring, and deep personal satisfaction from treating patients with medication and psychotherapy.

What is the most promising opportunity facing the profession?

Translating the explosive growth of basic neuroscience into clinical applications.

But it takes too long.

What is the greatest threat?

The dwindling number of psychiatric trainees who decide to pursue research careers. I am very concerned that financial constraints (e.g. student loans) prompt graduates to generate money rather than to generate new medical knowledge for the field, which will delay medical discoveries and breakthroughs.

What single change would substantially improve quality of care?

Discovering the real pathophysiology of psychosis, depression and anxiety disorders so that rational medications can be developed to replace the current unproven mechanisms of action.

\section{What conflict of interest do you} encounter most often?

Being objective about accepting or rejecting an article submitted by one of my close friends to one of the two journals I edit.

What is the most important advice you could offer to a new trainee?

(1) Making ethics and integrity a top priority; and (2) treat every patient as though they were a family member.

What are the main ethical problems that psychiatrists will face in the future?

(1) Arbitrating about the appropriateness of euthanasia for patients who request it; and (2) ethical use of genetic information on each patient.

What is the role of the psychiatrist in rebuilding healthcare systems?

The greatest service psychiatrists can do is to make sure a healthcare system adopts a biopsychosocial approach to all diseases in medicine.

What single change to mental health legislation would you like to see? Full access, full parity and an annual mental health checkup starting in childhood to enable early prevention and intervention.

What single area of psychiatric practice is most in need of development?

Evidence-based psychosocial interventions. There are far too many unproven treatments being practiced.

What single area of psychiatric research should be given priority?

Understanding and exploiting epigenetics so that mental illness can be modified or prevented via therapeutic epigenetic interventions even if a person inherits a risk gene(s).

How would you like to be remembered? A good husband and father, an effective psychiatric physician, teacher, mentor, researcher, editor and leader, and a fierce advocate for the mentally ill.

doi: 10.1192/pb.bp.111.036236 